\title{
Advantages of the new model of IRI (IRI-Plas) to simulate the ionospheric electron density: case of the European area
}

\author{
O. A. Maltseva, G. A. Zhbankov, and N. S. Mozhaeva \\ Institute for Physics, Southern Federal Universiy, Russia \\ Correspondence to: O. A. Maltseva (mal@ip.rsu.ru)
}

\begin{abstract}
Satellite telecommunications, positioning and navigation systems require knowledge of the electron distribution in height $\mathrm{Ne}(\mathrm{h})$ to high-altitude orbits of satellites. One of the possibilities to construct such profiles is associated with the use of the ionospheric total electron content TEC. This paper is devoted to three advantages of the IRIPlas model. They include introduction of the topside basis scale height Hsc, expansion of the IRI model to the plasmasphere, ingestion of experimental values of TEC. Testing of this model according to different satellite experiments (CHAMP, DMSP) shows the high efficiency of this model. The method of adaptation of the IRI-Plas model to the plasma frequency at altitudes of CHAMP and DMSP satellites allows us to produce behavior of $\mathrm{Ne}(\mathrm{h})$-profiles during the disturbances, as well as to refine the values of TEC, which determine the accuracy of positioning. Results were obtained using data of the European area.
\end{abstract}

\section{Introduction}

The operation of the various satellite communications, navigation, positioning systems depends on the state of the ionosphere and needs to know the electron distribution in height $\mathrm{Ne}(\mathrm{h})$ in near space. In application of radio and satellite communications, the empirical model of the ionosphere IRI (Bilitza, 2001) is most widely used, but it determines the $\mathrm{Ne}(\mathrm{h})$-profile to a height of $2000 \mathrm{~km}$. Ability to determine the profiles at higher altitudes is associated with the total electron content TEC. However, the IRI model gives a large discrepancy when compared with the experimental TEC because of the profile shape of the topside ionosphere, so that the model has been modified several times in this century (IRI2001, IRI2007, Bilitza, 2001; Bilitza, Reinisch, 2008) and the modification is continuing (in 2010, a new version of IRI2010 (Bilitza et al., 2010) was proposed). The next step can be connected with the IRI-Plas model based on papers of T. Gulyaeva (e.g. Gulyaeva, 2003, 2011). The main advantages of this model are introduction of the topside basis scale height Hsc, expansion of the IRI model to the plasmasphere, ingestion of experimental values of TEC. Previous versions allowed us to adapt the model to two experimental parameters of the ionosphere: the critical frequency foF2 and the maximum height hmF2. Now there are three parameters. This should allow to determine the more precise shape of $\mathrm{Ne}(\mathrm{h})$-profiles. The aim of this work is: (1) determination of the behavior of $\mathrm{Ne}(\mathrm{h})$-profiles when adapting the model to three parameters, (2) clarification of the values of TEC by means of adaptation of the model to the plasma frequency fne(sat) at altitudes of satellites CHAMP and DMSP. The IRI-Plas model was taken from site ftp://ftp.izmiran.rssi.ru/ pub/izmiran/SPIM/. The values of the parameters foF2 and $\mathrm{hmF} 2$ are taken from the database (http://spidr.ngdc.nasa. gov/spidr/index.jsp), TEC values are taken from IONEX files of global maps of JPL, CODE, UPC, ESA (ftp://cddis. gsfc.nasa.gov/pub/gps/products/ionex/). Data of fne(sat) was taken from http://cindispace.utdallas.edu/DMSP/dmsp_ data_at_utdallas.html (Langmuir Probe Data), http://isdc. gfz-potsdam.de/. Juliusruh is chosen as a reference station. In addition, the results for other stations of the European area are presented.

\section{Testing the model IRI-Plas according to different experiments}

Testing by means of satellite data is carried out for 4 cases used in various applications: (1) the initial model IRI, and models adapted to: (2) the experimental value of foF 2 , (3) the experimental value of the TEC, (4) experimental values of foF 2 and TEC, to demonstrate the difference between the results for these methods. Option 1 is used when there is no current information, and determines the average (quiet) 


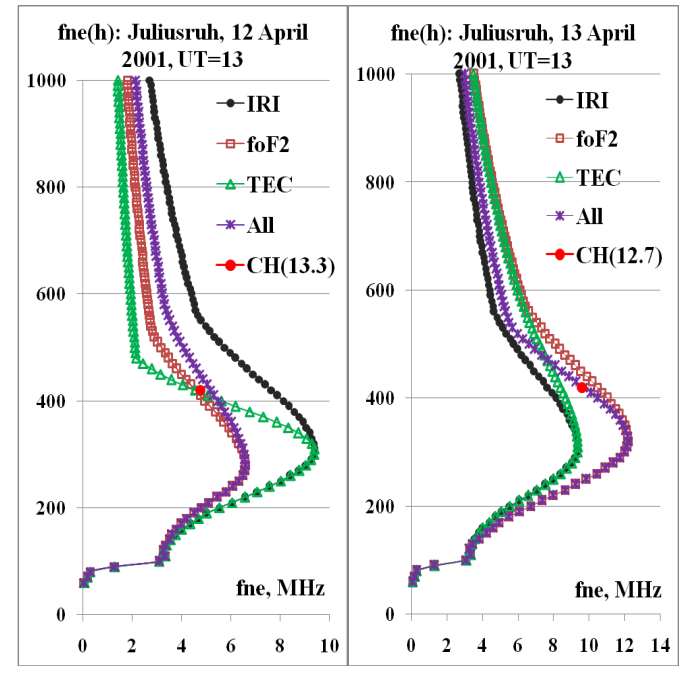

Fig. 1. Comparison of $\mathrm{Ne}(\mathrm{h})$-profiles corresponding to the initial IRI model (black circles) with $\mathrm{Ne}(\mathrm{h})$-profiles of the model adapted to experimental values of foF 2 (red squares), experimental values of TEC (green triangles) and joint values of foF 2 and TEC (violet asterisks). The red circles show values of the plasma frequency of the CHAMP satellite. The left panel illustrates case of the positive disturbance, the right panel applies to negative one.

ionospheric state. It is a standard for comparison with other options. Option 2 uses the current value of foF 2 and completely defines the bottom side of the profile. Option 3 is widely used in connection with the TEC measurements. The advantages of this option before the second one are in a continuous global monitoring. Adapting the model to the current values of the TEC allows us to obtain new values of foF2. Option 4 is one of the main differences between the IRI-Plas model and previous IRI versions. It allows to determine the $\mathrm{Ne}(\mathrm{h})$-profile at the location of ionosondes. Testing of these options is to compare the plasma frequency at altitudes of satellites calculated for the model with the experimental values of fne. A comparison was carried out for two satellites CHAMP (hsat $\sim 400 \mathrm{~km}$ ) and DMSP (hsat $\sim 840 \mathrm{~km}$ ). Results are given for April 2001, including two strong and two weak disturbances. Figure 1 displayes cases related to the negative and positive perturbations.

A substantial difference between foF2(obs) and foF2(IRI) is seen. The profiles shown by black dots present the profiles for the initial model. The profiles shown by green triangles correspond to the traditional adaption techniques when the construction of $\mathrm{N}(\mathrm{h})$-profile uses the experimental value of the TEC and the model value of foF2 (McNamara, 1985; Houminer and Soicher, 1996, Gulyaeva, 2003), as well as assimilation techniques involving TEC (e.g., Khattatov et al., 2005). The difference can be large. The best agreement corresponds to the new version. It allows us to illustrate how can change N(h)-profiles, adapted to the foF2 and TEC during the disturbances of various types.

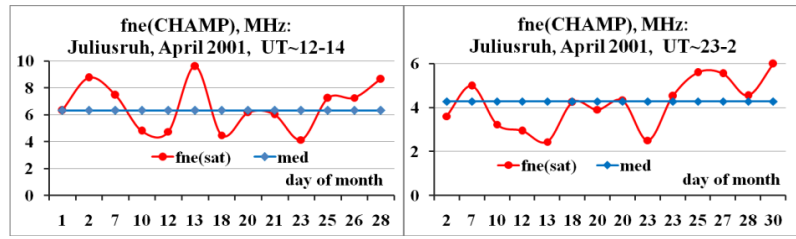

Fig. 2. The behavior of the plasma frequency fne(CHAMP) near noon (left panel) and midnight (right panel) along with medians of these values to detect periods of positive and negative disturbances in the topside ionosphere.

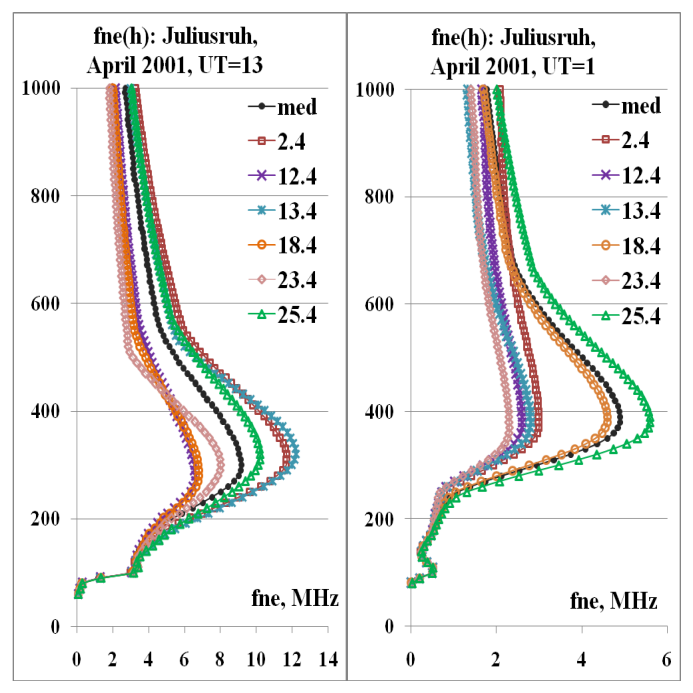

Fig. 3. The behavior of $\mathrm{Ne}(\mathrm{h})$-profiles during disturbances in April 2001. Black circles display the median profiles obtained by the model adapted to experimental medians of foF 2 and TEC. The other profiles apply to days indicated by corresponding marks. The left panel concerns to time near noon $(\mathrm{UT}=13)$, the right panel - time near midnight $(\mathrm{UT}=1)$.

\section{Examples of the behavior of $\mathrm{Ne}(\mathrm{h})$-profiles during the disturbances}

Figure 2 shows the behavior of the plasma frequency fne(sat) according to CHAMP satellite in April 2001 over the Juliusruh station, along with the median to detect cases of disturbances in the upper ionosphere. In the left panel are cases that fall near noon, on the right side - near midnight. Figure 3 shows $\mathrm{Ne}$ (h)-profiles for the Juliusruh station together with $\mathrm{Ne}(\mathrm{h})$-profiles calculated for the experimental medians of foF 2 and TEC (the lines shown by black dots).

A positive deviation is seen for the daytime. At night, negative deviations dominate with lower gradients in the topside. Another example refers to a period of quiet Sun, which attracted a great attention of the scientific community because of the unusual duration (e.g. Liu et al., 2011; Zakharenkova et al., 2011). In terms of the perturbation this 


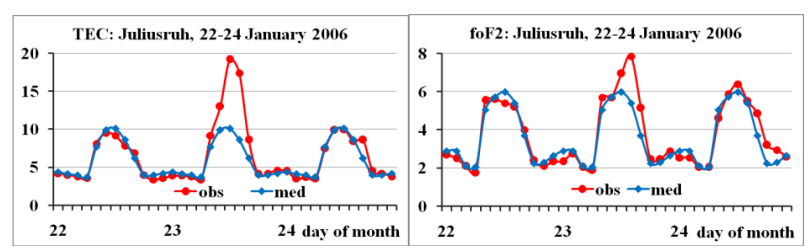

Fig. 4. Typical example of the TEC burst and corresponding variation of foF2: "obs" presents experimental values, "med" shows medians.

period is characterized by the absence of strong and moderate disturbances. The disturbances were observed in the form of positive bursts of TEC (Cander and Haralambous, 2011) synchronously covering the European zone from Chilton to Athens. Example of the TEC burst and corresponding variation of foF2 for the Juliusruh station for 22-24 January 2006 is displayed in Fig. 4. Behavior of $\mathrm{Ne}(\mathrm{h})$-profiles for these days and UT $=8-18$ is given in Fig. 5 along with profiles for medians. At the time UT $=8, \mathrm{Ne}(\mathrm{h})$-profiles are still little different from the medians. At the time UT $=10$, only ionization of the topside part increased. At the time UT = 12 , a gain propagated to lower ionosphere, reaching a maximum at $\mathrm{UT}=14$. At the time UT $=16$, decrease in the ionization of the topside part occurred most rapidly. At the time UT $=18$, peaks of TEC and foF2 have completely disappeared. This illustrates that development of disturbance is connected with transition of ionization from plasmasphere to the region near the F2 maximum. This behavior is characteristic for other mid latitude stations (Chilton, Ebre, Athens, Leningrad, Moscow), and for other cases. Different behavior of $\mathrm{Ne}(\mathrm{h})$-profiles is visible for the Tromso station, as shown in Fig. 6. The perturbation starts earlier (at UT $=0$ ) and passes the maximum phase in $\mathrm{UT}=12$. Some profiles seem unusual, but a comparison of profiles in the times when measurements of fne were in the satellite CHAMP (Fig. 7) shows a complete coincidence for adapted profiles. Since it is difficult to obtain the moments of coincidence between measurements of the satellite and the TEC, Fig. 7 shows the results for the nearest moments that are indicated in parentheses. The difference between profiles for four versions is great.

The above examples show that the profiles adapted to both of the foF 2 and TEC parameters can be an important tool for studying the behavior of the ionosphere. N(h)-profiles adapted to one of the parameters may be far away from the real profiles.

\section{Refinement of the TEC values from satellite experiments}

There is a variety of the TEC values, which can be used to adapt the model. These are: (1) measurement at individual receivers, the values of which can differ up to $\sim 10$ TECU

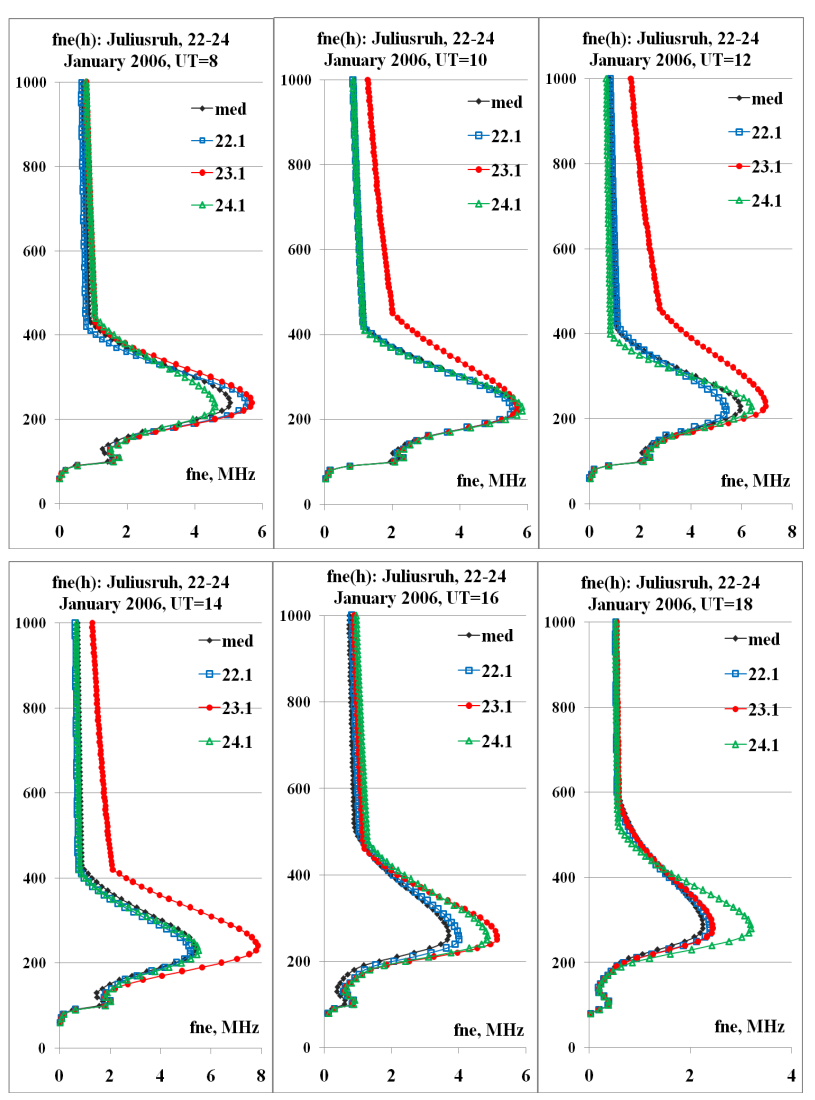

Fig. 5. The behavior of $\mathrm{Ne}(\mathrm{h})$-profiles during the burst of TEC on 22-24 January 2006 over the Juliusruh station. The Ne(h)-profiles shown by black circles were obtained by the model adapted to experimental medians of foF 2 and TEC. The $\mathrm{Ne}(\mathrm{h})$-profiles shown by red circles apply to the day of the burst (23 January 2006).

of each other (e.g. Choi et al., 2010), (2) the global maps, the values of which can differ up to 2-3 times (Arikan et al., 2003), (3) tomographic measurements (Chartier et al., 2012) and others. A typical example of differences was done in Fig. 7 of the paper (Arikan et al., 2003). This Figure compares TEC values obtained by various methods: authors of Arikan et al. (2003), Rutherford Appleton Laboratory (Ciraolo and Spalla, 1997), Canadian maps and four IGS maps for the Kiruna station on 25 and 28 April 2001 (difference in 2-3 times). We had only the values of global maps of JPL, CODE, UPC, ESA. The values of these maps for the Juliusruh station on 25 April are shown in our Fig. 8 (the left panel): the difference for four maps may lie in the range of 10-30 TECU. This set of values leads to variety of $\mathrm{N}(\mathrm{h})$-profiles that differ greatly from each other. It is difficult to specify the criterion to select the TEC close to the true value. But there is a criterion for choosing $\mathrm{N}(\mathrm{h})$-profiles. This is measurement of the plasma frequency fne(sat) on the satellites. Of two satellites, DMSP should be preferred due to a high-altitude orbit and the values of CHAMP sometimes meet several profiles. $\mathrm{Ne}(\mathrm{h})$-profiles adapted to fne(DMSP) 


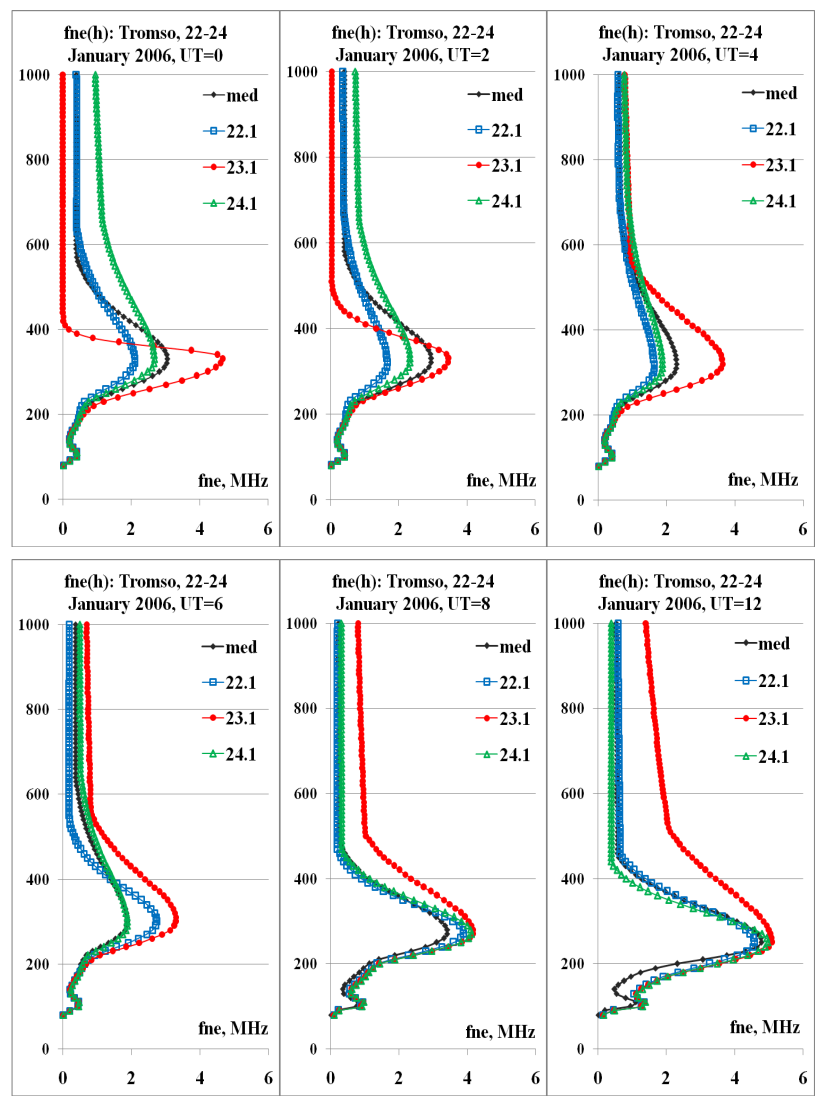

Fig. 6. The behavior of the $\mathrm{Ne}(\mathrm{h})$-profiles during the burst of TEC on 22-24 January 2006 for the Tromso station. Designations are the same as on Fig. 5.

provide new values of the TEC, which are different from the values of all global maps. The right panel of Fig. 8 shows these values for two days (25, 28 April 2001) and time of satellite passages indicated in parenthesis. For example, 25(9) means 25 April 2001 and UT $=9$. Another example is presented in Fig. 9 for the Moscow station and other disturbed month (July 2004).

These examples and statistics from many stations and geophysical conditions show that the values of TEC corresponding fne(DMSP) may lie within the range of maps below the weighted average IGS values (Hernandez-Pajares et al., 2009), but may be below that range.

\section{Conclusions}

TEC is the most important parameter of the ionosphere used in scientific and engineering applications, so there is a need of its model. One such model is the IRI. This paper deals with the IRI-Plas version of this model, which has advantages of a rigorous account of the plasmaspheric part of the profile, the introduction of Hsc parameter to determine the shape of the upper part of the profile, ingestion of the TEC. We used
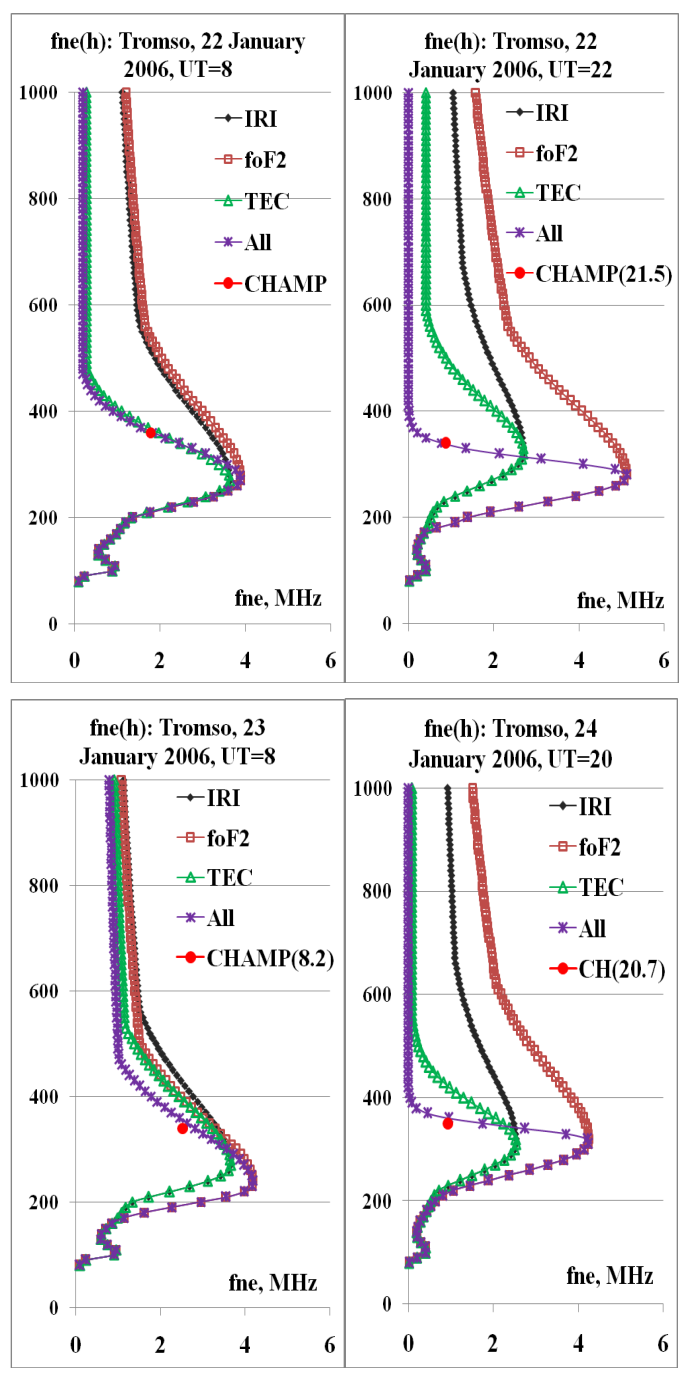

Fig. 7. $\mathrm{Ne}$ (h)-profiles during the burst of TEC on 22-24 January 2006 in the Tromso station at moments, close to passages of the satellite.

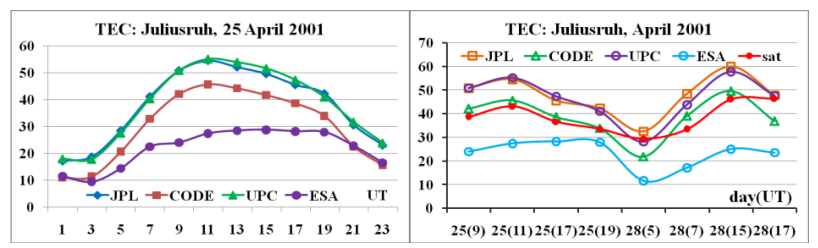

Fig. 8. Differences of TEC calculated from the various global maps (left panel) and TEC obtained by adaptation of the model to the plasma frequency fne of the DMSP satellite (right panel).

these advantages to show: (1) the adaptation of the model to the TEC has provided $\mathrm{Ne}(\mathrm{h})$-profiles, very different from the profiles of the original model, and allows to assess the behavior of the ionosphere during the disturbances, (2) due to the variety of values of TEC, adaptation of the model to 


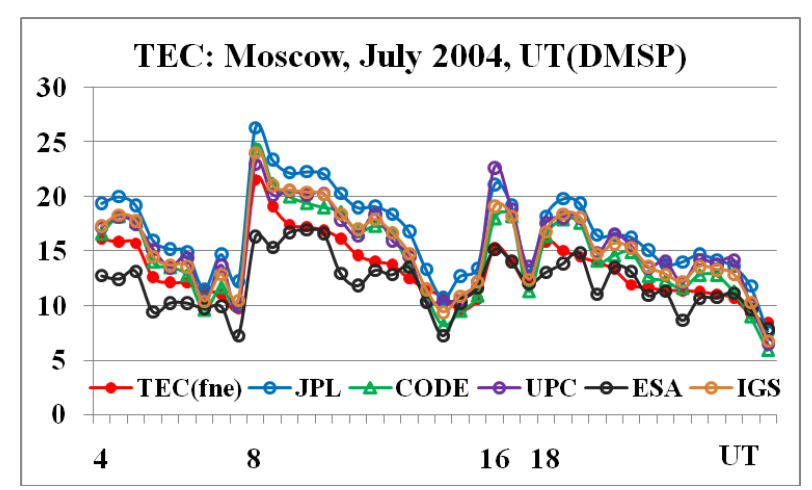

Fig. 9. New TEC values in comparison with data of global maps of JPL, CODE, UPC, ESA and weighted average IGS values. Results are given for days (not shown in the figure) and time UT of the satellite passages indicated on the $\mathrm{x}$-axis.

one of the parameters, or even three parameters (foF2, hmF2, TEC) does not always lead to the $\mathrm{Ne}(\mathrm{h})$-profile corresponding plasma frequencies fne(sat), and (3) an adaptation of the model to fne(sat) can lead to new values of TEC, which can lie within the existing set of values, and may be below that set. We can point to two possible ways to use these values. If we can specify a value of "true" TEC, the difference can be attributed to the plasmaspheric part and thus we get the way of correction of this part, which is still of some interest (e.g., Cherniak et al., 2012). If this value cannot be specified, then the values of TEC for profiles adapted to fne(sat), can be considered as an improved value of the TEC. For applications in navigation and positioning, an empirical ionospheric model should be used to minimize the ionospheric errors. The Klobuchar model (e.g., Klobuchar, 1987) widely used for this aim provides a $50 \%$ correction on a global basis. It is possible to suppose that the IRI-Plas model can compensate the ionospheric error with much higher accuracies. These results and conclusions were obtained for the European region. It is not difficult to obtain such results for any other region of the globe.

Acknowledgements. Authors thank scientists provided data of SPIDR, global maps of TEC, operation and modification of the IRI model, A. Karpachev for CHAMP data, two reviewers for very important comments.

\section{References}

Arikan, F., Erol, C. B., and Arikan, O.: Regularized estimation of vertical total electron content from Global Positioning System data, J. Geophys. Res., 108, 1469, doi:10.1029/2002JA009605, 2003.

Bilitza, D.: International Reference Ionosphere, Radio Sci., 36, 261-275, 2001.
Bilitza, D. and Reinisch, B. W.: International Reference Ionosphere 2007: Improvements and New Parameters, Adv. Space Res., 42, 599-609, 2008.

Bilitza, D., Reinisch, B. W., and Gulyaeva, T.: ISO technical specification for the ionosphere - IRI recent activities, in: Report presented for COSPAR Scientific Assembly, Bremen, Germany, C01-0004-10, 2010.

Cander, L. R. and Haralambous, H.: On the importance of TEC enhancements during the extreme solar minimum, Adv. Space Res., 47, 304-311, 2011.

Chartier, A., Mitchell, C. N., and Jackson, D. R.: A 12 year comparison of MIDAS and IRI2007 ionospheric total electron content, Adv. Space Res., 49, 1348-1355, 2012.

Cherniak, Iu. V., Zakharenkova, I. E., Krankowski, A., and Shagimuratov, I. I.: Plasmaspheric electron content from GPS TEC and FORMOSAT-3/COSMIC measurements: solar minimum conditions, Adv. Space Res., 50, 427-440, 2012.

Choi, B.-K., Chung, J.-K., and Cho, J.-H.: Receiver DCB estimation and analysis by types of GPS receiver, J. Astron. Space Sci., 27, 123-128, 2010.

Ciraollo, L. and Spalla P.: Comparison of ionospheric total electron content from the Navy Navigation Satellite System and the GPS, Radio Sci., 32, 1071-1080, 1997

Gulyaeva, T. L.: International standard model of the Earth's ionosphere and plasmasphere, Astron. and Astrophys. Transaction, 22, 639-643, 2003.

Gulyaeva, T. L.: Storm time behavior of topside scale height inferred from the ionosphere-plasmosphere model driven by the F2 layer peak and GPS-TEC observations, Adv. Space Res., 47, 913-920, 2011.

Hernandez-Pajares, M., Juan, J. M., Orus, R., Garcia-Rigo, A., Feltens, J., Komjathy, A., Schaer, S. C., and Krankowski, A.: The IGS VTEC maps: a reliable source of ionospheric information since 1998, J. Geod., 83, 263-275, 2009.

Houminer, Z. and Soicher, H.: Improved short-term predictions of foF2 using GPS time delay measurements, Radio Sci., 31, 10991108, 1996.

Khattatov, B., Murphy, M., Gnedin, M., Sheffel, J., Adams, J., Cruickshank, B., Yudin, V., Fuller-Rowell, T., and Retterer J.: Ionospheric nowcasting via assimilation of GPS measurements of ionospheric electron content in a global physics-based timedependent model, Q. J. Roy. Meteorol. Soc., 131, 3543-3559, 2005.

Klobuchar, J. A.: Ionospheric time-delay algorithm for singlefrequency GPS users, IEEE Transactions on aerospace and electronic systems, AES-23, 325-331, 1987.

Liu, L., Chen, Y., Le, H., Kurkin, V. I., Polekh, N. M., and Lee, C.C.: The ionosphere under extremely prolonged low solar activity, J. Geophys. Res., 116, A04320, doi:10.1029/2010JA016296, 2011.

McNamara, L. F.: The use of total electron density measurements to validate empirical models of the ionosphere, Adv. Space Res., 5, 81-90, 1985.

Zakharenkova, I. E., Krankowski, A., Bilitza, D., Cherniak, Yu. V., Shagimuratov, I. I., and Sieradzki, R.: Comparative study of foF2 measurements with IRI-2007 model predictions during extended solar minimum, Adv. Space Res., 51, 620-629, 2011. 